\title{
Autoanticorpos em pacientes com hanseníase e leishmaniose - mais evidência da associação entre infecções e autoimunidade
}

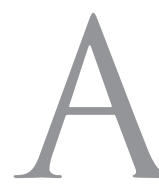
associação entre doenças infecciosas e autoimunidade, apresentando-se com manifestações clínicas ou detectada apenas pelo desenvolvimento de autoanticorpos, tem sido amplamente documentada ${ }^{1}$. Infecções virais, bacterianas e parasitárias podem estar envolvidas no desenvolvimento, recaída e até mesmo na prevenção de doenças auto-imunes ${ }^{1,2}$. Esse exemplar da RBR apresenta dois estudos sobre a prevalência de autoanticorpos em pacientes com doenças infecciosas. Riebeiro e col. avaliaram a frequência de fator reumatóide (FR), anticorpos antipeptídeo citrulinado cíclico (anti-CCP), anticorpos antinucleares (AAN), anticorpos anti-citoplasma de neutrófilos (ANCA), anticorpos anticardiolipina (aCL) e anticorpos anti- $\beta 2$ glicoproteína I (anti- $\beta 2 \mathrm{GPI}$ ) em pacientes com hanseníase. Dos 158 pacientes avaliados, 76 pacientes apresentavam manifestações articulares, enquanto 82 não apresentavam envolvimento articular. $\mathrm{O}$ grupo controle consistia de 129 indivíduos saudáveis com idade e gênero semelhantes aos dos pacientes estudados e que residiam na mesma área geográfica. A maioria dos pacientes nos dois grupos (com e sem envolvimento articular) apresentava hanseníase generalizada (VV). Os autores observaram uma baixa frequência, que não foi significativamente diferente, de FR, anti-CCP, AAN e ANCA em pacientes com hanseníase (nos dois grupos) e normal dos controles. Mas a prevalência de anticorpos aCL e anti-ß2GPI estava significativamente elevada nos pacientes com hanseníase quando comparados com o grupo controle, apesar de não haver associação significativa com o envolvimento articular. O isotipo predominante dos dois autoanticorpos foi a IgM. Quase metade (48.7\%) dos pacientes com hanseníase apresentava pelo menos um anticorpo antifosfolípide. Além disso, os autores observaram uma associação entre a positividade para aCL e as manifestações clínicas, já que os pacientes com anticorpos aCL apresentavam doença VV generalizada com mais frequência $(p=0.002)$. Não houve associação entre a presença de anticorpos aCL ou anti- $\beta 2 \mathrm{GPI}$ e episódios reacionais; porém, entre os pacientes com esses episódios, aqueles com anticorpos aCL apresentavam ENH em $100 \%$ dos casos, enquanto entre os pacientes negativos para aCL, 57\% apresentavam ENH. Apesar de uma alta taxa de concordância para a presença de anticorpos aCL e antiß2GPI ter sido observada, manifestações tromboembólicas não foram observadas.

No segundo estudo, Harimoto e col. avaliaram 90 pacientes com Leishmania (45 pacientes apresentavam leishmaniose visceral e 45 pacientes apresentavam leishmaniose cutânea) para a presença de anticorpos anti-Leishmania, assim como FR, AAN, anti-DNA, anti-Sm, anti-RNP, anti-Ro, anti-La e aCL e complemento (C3 e C4). Como esperado, $100 \%$ dos pacientes com leishmaniose visceral apresentava anticorpos anti-Leishmania contra $62.3 \%$ dos pacientes com doença cutânea limitada. Títulos significativamente elevados de AANs (apesar de pouco elevados em alguns pacientes), mas não de anti-DNA, foram detectados em apenas $4.4 \%$ dos pacientes com doença visceral, assim como títulos elevados de anticorpos aCL (isotipo IgG), quando comparados com os pacientes com leishmaniose cutânea. Níveis reduzidos de complemento também eram evidentes nos pacientes com doença visceral (13.3\% dos pacientes apresentavam níveis significativamente reduzidos de $\mathrm{C} 3$ ).

Nos dois estudos, os autores compararam e discutiram seus resultados em relação à crescente evidência na literatura da presença de autoanticorpos em ambas as doenças. Alguns dos seus resultados são consistentes com estudos anteriores, mas diferem de outros. Em geral, a prevalência variável de autoanticorpos relatada nos dois estudos, assim como relatos prévios na literatura, pode estar relacionados a diferenças metodológicas, como o tipo de ensaio utilizado, a definição dos pontos de corte, inativação dos soros pelo calor, seleção de pacientes e variações étnicas e geográficas nos grupos de pacientes. Mas um dos resultados consistentes nos dois estudos 
foi a frequência significativamente mais elevada de anticorpos antifosfolípides, aCL e anti- $\beta 2 / G P I$, em pacientes com hanseníase do que no grupo controle, enquanto anticorpos AAN e aCL foram detectados com mais frequência nos pacientes com leishmaniose visceral. A incidência aumentada de anticorpos AAN e aCL nos pacientes com leishmaniose visceral é compatível com relatos e estudos prévios ${ }^{3-5}$ e ilustra as similaridades das manifestações clínicas e laboratoriais entre a leishmaniose visceral e o lúpus eritematoso sistêmico (LES). Além disso, a reatividade cruzada entre AAN e anticorpos anti-Leishmania já foi relatada ${ }^{6}$.

Diversos grupos documentaram níveis elevados de anticorpos antifosfolípides (aCL, anti- $\beta 2 \mathrm{GPI}$ e anti-protrombina) em diversas doenças infecciosas, como a sífilis, doenças virais (incluindo a hepatite C, Parvo B19 e HIV), malária e hanseníase, sem as manifestações clínicas da síndrome antifosfolípide (SAF) ${ }^{7}$. Os títulos elevados geralmente são transitórios, diminuindo e desaparecendo após a resolução da infecção ${ }^{7-9}$. Mas, em uma minoria dos pacientes, a associação entre doenças infecciosas anticorpos antifosfolípides pode levar a complicações severas, frequentemente fatais, ou seja, "SAF catastrófica" .

Os resultados de Ribeiro e col. mostrando um aumento da incidência de anticorpos anti- $\beta 2$-GPI em pacientes com hanseníase, associados aos dados de nosso grupo e outros ${ }^{9-12}$, que também documentaram níveis elevados de anticorpos anti$2 \beta G P I$ nesses pacientes, lançam dúvidas sobre a noção de que os anticorpos aCL associados a infecções são independentes dos anticorpos anti- $\beta 2 \mathrm{GPI}$, e não dependentes desses anticorpos, como nas doenças auto-imunes. Em conjunto, esses resultados apóiam a noção de que, na presença de infecções, anticorpos $\mathrm{aCL}$ são heterogêneos em relação à sua dependência da $2 \mathrm{GPI}^{9-}$ ${ }^{12} \mathrm{e}$ as infecções podem desencadear a indução de anticorpos antifosfolípide "patogênicos" em indivíduos predispostos9.

A produção de autoanticorpos na hanseníase e leishmaniose pode ser explicada por diversos mecanismos. Na forma mais generalizada dessas doenças (hanseníase VV e leishmaniose visceral), os pacientes apresentam hipergamaglobulinemia difusa semelhante à vista em outras infecções, como Schistosoma mansoni, T. cruzi e Plasmodium. A indução de autoanticorpos pode ser atribuída à ativação policlonal e proliferação das células $\mathrm{B}$, algumas com auto-reatividade, pertencentes à biblioteca de anticorpos naturais em indivíduos normais ${ }^{13}$. Na leishmaniose, antígenos solúveis derivados da L. major e $L$. donovani são mitogênicos e desencadeiam a produção de imu- noglobulinas com auto-reatividade ${ }^{13}$. Crioglobulinemia mista induzida pelo HCV é outro exemplo de ativação policlonal persistente levando a uma mistura de autoanticorpos policlonais e monoclonais, os quais causam doenças auto-imunes ${ }^{14}$.

Mimetismo molecular ou homologias estruturais entre infecções e componentes do hospedeiro podem ser a base da produção de autoanticorpos, como no caso da febre reumática, onde o componente $\mathrm{M}$ da membrana do estreptococo apresenta homologia com peptídeos cardíacos, cerebrais e sinoviais. A associação da síndrome de Guillain-Barré com a infecção pelo Campylobacter jejeuni representa outro exemplo de mimetismo molecular como base de uma manifestação auto-imune. A reatividade cruzada entre agentes infecciosos e auto-antígenos já foi demonstrada para o M. leprae ${ }^{15}$ e M. tuberculosis ${ }^{16}$, e a inibição de anticorpos anti-Sm, anti-RNP e anti-SSB por promastigotas intactas de Leishmania apóia a homologia entre antígenos nucleares e a Leishmania ${ }^{13}$.

A disseminação de epítopos, a emergência de novos anticorpos ou a resposta de células $\mathrm{T}$ a um novo epítopo (subdominante ou críptico) no mesmo antígeno ou em outro antígeno foi demonstrada em modelos experimentais e na doença humana. Alguns autores demonstraram a disseminação molecular do antígeno $\mathrm{Sm}$ para reatividade anti-RNP ${ }^{17}$, no LES, enquanto na febre reumática, o estado de autoimunidade crônica que afeta as válvulas cardíacas pode resultar em uma resposta imunológica contra o colágeno e laminina ${ }^{1,2}$. As infecções também podem desempenhar um papel importante na indução da autoimunidade através da liberação de antígenos seqüestrados, após lesão tecidual, ou aumentando a exibição de epítopos crípticos, no meio inflamatório, apresentando, assim, novos antígenos ao sistema imunológico.

Resumindo, os dois novos estudos publicados nesse exemplar da RBR apresentam novos conhecimentos para nossa crescente compreensão da relação intricada entre infecções e autoimunidade e, especificamente, em relação a anticorpos antifosfolípides em indivíduos suscetíveis, as infecções podem induzir o desenvolvimento de anticorpos antifosfolípides patogênicos.

\section{Martine Szyper-Kravitz}

Centro de Doenças Autoimunes e Departamento B de Medicina, Chaim Sheba Medical Center Tel-Hashomer, Sackler Faculty of Medicine, Tel Aviv University, Israel. 


\section{REFERÊNCIAS}

\section{References}

1. Pordeus V, Szyper-Kravitz M, Levy RA, Vaz NM, Shoenfeld Y. Infections and autoimmunity: a panorama. Clin Rev Allerg Immunol 2008;34:283-299.

2. Kivity S, Agmon-Levin N, Blank M, Shoenfeld Y. Infections and autoimmunity - friends or foes? Trends Immunol 2009;30:409-414.

3. Voulgari PV, Pappas G, Liberopoulos EN, Elisaf M, Skopouli FN, Drosos AA. Visceral leishmaniasis resembling systemic lupus erythematosus. Ann Rheum Dis 2004;63:1348-1349.

4. Ossadron A, Bompane D, Alessandri C, Marocchi E, Conti F, Vaesini G. Leishmania in systemic lupus erythematosus mimicking an exacerbation. Clin Exp Rheumatol 2006;24:186-190.

5. Sakkas LI, Boulbou M, Kyriakou D, Makri I, Sinani C, Germenis A, Stathakis N. Immunological features of visceral leishmaniasis may mimic systemic lupus erythematosus. Clin Biochem 2008;41:65-68.

6. Granel B, Serratrice J, Swiader L, Gambarelli F, Daniel L, Fossat C, Hesse-Bonerandi S, Pache X, Disdier P, Weiller PJ. Crossing of antinuclear antibodies and anti-leishmania antibodies. Lupus 2000;9:548-550.

7. Zandman-Goddard G, Blank M, Shoenfeld Y. Antiphospholipid antibodies and infections-drugs. In: Asherson RA, Cervera R, Piette JC, Shoenfeld Y, eds. The antiphospholipid syndrome II. Amsterdam: Elsevier Science, 2002: 343-360.

8. Guedes Barbosa LS, Gilburd B, Shoenfeld Y, Scheinberg MA. Autoantibodies in lepra sera. Clin Rheumatol 1996;15:26-28.

9. Loizou S, Singh S, Wypkema E, Asherson RA. Anticardiolipin, anti- $\beta 2$-glycoprotein I and antiprothrombin antibodies in black South African patients with infectious disease. Ann Rheum Dis 2003;62:1106-1111.
10. De Laranaga GF, Forastiero RR, Martinuzzo ME, Carreras MO, Tsariktsian G, Surno MM et al. High prevalence of antiphospholipid antibodies in leprosy: evaluation of antigen reactivity. Lupus 2000;9:594-600.

11. Hojnik M, Gilburd B, Ziporen L, Blank M, Tomer Y, Scheinberg MA et al. Anticardiolipin antibodies in infections are heterogenous in their dependency on $\beta 2$-glycoprotein I: analysis of anticardiolipin antibodies in leprosy. Lupus 1994;3:515-521.

12. Fiallo P, Travaglina C, Nunzi E, Cardo PP. $\beta 2$-glycoprotein I dependence of anticardiolipin antibodies in multibacillary leprosy patients. Lepr Rev 1998;69: 376-381.

13. Argov S, Jaffe CL, Krupp M, Slor H, Shoenfeld Y. Autoantibody production by patients infected with Leishmania. Cin Exp Immunol 1989;76:190-197.

14. Agmon-Levin N, Ram M, Barzilai O, Porat-Katz BS, Parikman R, Selmi C, Gershwin ME, Anaya JM, Youinou P, Bizzaro N et al. Prevalence of hepatitis $\mathrm{C}$ serum antibody in autoimmune diseases. J Autoimmun 2009;32:261-266.

15. McAdam KPWJ, Mudd D, Shoenfeld Y. Autoantibodies to DNA in leprosy: antigenic similarities between DNA and mycobacterial phospholipids defined by human monoclonal antibodies. Int J Lepr Suppl 1984; 52:697.

16. Shoenfeld Y, Vilner Y, Coates ARM, Rauch J, Lavie G, Shaul D, Pinkhas J. Monoclonal anti-tuberculosis antibodies react with DNA, and monoclonal anti-DNA autoantibodies react with Mycobacterium tuberculosis, Clin Exp Immunol 1986;66:255.

17. Shoenfeld Y, Rose NR. Infection and autoimmunity, Amsterdam: Elsevier,2004. 